\title{
Shifts in the Direction of Dutch Bioethics: Forward or Backward?
}

\author{
GERRIT K. KIMSMA and EVERT VAN LEEUWEN
}

Important bioethcs changes are underway in the Netherlands that carry, for better or worse, far-reaching social consequences. The two major areas of change involve (1) economics and containing soaring health costs and (2) end-of-life care as reflected in several high-profile cases: in a decision handed down by the Dutch Supreme Court on reviewing the procedures for the termination of life, in the discussion surrounding The Groningen Protocol and the active ending of lives in neonatology, and in a report of a Royal Dutch Medical Society's Committee on the role of physicians in ending life in cases of requests to die outside the area of terminal diseases.

Each of these events and reports is described in broad outline below.

\section{Economics}

An appeal to Adam Smith's "invisible hand" as a solution for rising health care costs? ${ }^{1}$ For the past decades soaring healthcare costs have become a major source of worry for governments, institutions, and individuals in all Western countries. In response, Dutch politics has moved away from state-controlled socialized welfare by distancing state involvement, by delegating the management and control of social tasks to the direct stakeholders, and by converting former state institutions into private enterprises, thus creating a "government at a distance" policy. Successive governments, formed by Liberals, Social Democrats, and Christian Democrats, have made a significant departure from the traditional two-tiered system of healthcare insurance introduced during the Second World War that was modeled after the German system. Until now there has been mandatory insurance for lower income groups and voluntary insurance for the higher income classes.

Several changes with moral significance for the system have already been decided or are intended for future implementation. The concept of "solidarity" as the basis for payment (i.e., the plan in which people pay a fee commensurate with their risk and the funds collected are sufficient to cover expenditures but produce no profit) is being replaced. Instead, the new plan is for a system of obligated insurance that provides a basket of basic primary healthcare provisions, with options for individuals to get supplemental coverage for risks not otherwise covered. Thus, there is a shift away from state-centered responsibility in which the state controls the price of healthcare premiums in contrast to the market setting the price without government interference. Not-for-profit institutions have become for profit, more or less like making the foxes responsible 
for guarding the chicken coop. This combination of individualization and commercialization is the latest expression of the liberal ideology of individual responsibility, in the European sense, and faith in market mechanisms. The intended and hoped for effects are competition in the formerly nonprofit section of public life and a lowering of costs or at least more resistance toward the usual open-ended funding of healthcare provisions. This "invisible hand" ideology of Adam Smith is partly driven by the need to be more competitive in the European and international markets, requiring a general reduction of production costs and, subsequently, a lowering of the cost of insurance coverage.

Two of the most visible expressions of these changes are the introduction in 2005 of Diagnostic Related Groups (DRGs) in hospital-provided care and the introduction of a "no claim" system for individuals. The expectation of DRGs as a cost-containment measure would seem questionable after its failure in the United States.

The introduction of a "no claim" measure seems a definite farewell to solidarity, because the rationale is that nonusers of healthcare will receive a rebate if and when few or no claims for healthcare have been made. The idea behind this move is to weed out "unnecessary" use of healthcare provisions, as if expressing complaints and claims for help are matters of conscious choice, comparable to buying goods in the marketplace. This threshold works against those people whose healthcare needs are not elective but required: the chronically ill, the very young, and the elderly. The first effect of this "no claim" scheme has been a rise in health insurance costs for all individuals, regardless of their health status.

\section{End of Life}

There have been three landmark events. First, the Dutch Supreme Court ("Hoge Raad") upheld a conviction by a lower court of a family physician who ended the life of an 85-year-old terminal patient, without the presence of a request and with the incorrect medication. The message of the Court was clear, and the limits of the law on "Review procedures for the termination of life on request and assisted suicide etc." were upheld, as expected. This decision is noteworthy because it is only the fourth decision on interventions at the end of life by the Hoge Raad, and it reaffirms the position that the request of the patient is fundamental in cases of ending lives.

Second, there was a brief but intense wave of reaction when it became public that in 2004 the Beatrix Paediatric Clinic of the Groningen Academic Medical Center had ended the lives of four neonates, using a protocol and having discussed the cases with the legal authorities without ensuing prosecution. The protocol, called the "Groningen Protocol," comes as the result of decades of debate, both inside and outside the Netherlands. ${ }^{2}$

Steps taken in the Groningen Protocol are an attempt to resolve a dilemma that has been widely recognized by pediatricians and law enforcement officers, that is, the existence of a group of extremely premature neonates who remain viable after intensive treatment, sometimes despite decisions not to treat, but whose condition is one of hopeless suffering, without prospects for any sort of independent life. ${ }^{3}$ The medical diagnoses of the neonates were severe brain damage from bleeding, extreme spina bifida, and epidermolysis bullosa, an extreme, lethal blistering disease of the skin. 
The announcement of the protocol has come in a period where the original intention was to plan a national review committee in the area of life-ending interventions for incompetent patients: neonates and young children, severely retarded people, and comatose patients. It appears that this committee will not be convened for some time to come and thus the problem is left with the medical profession. The Groningen Protocol can be seen as an expression of the direction in which "the field" is moving.

In Groningen the decision has been made to report all cases of actively ending a life to the legal authorities, thus making a choice for transparency, based on previous court cases of Prins, Kadijk, the Law on Review Procedures for the Termination of Life on Request or Assisted Suicide (2002), and professional policy reports of the Royal Dutch Medical Association (RDMA) and the Dutch Society of Paediatricians.

The Protocol specifies the following procedural steps: Following the active termination of the life of a neonate, the physician in charge submits an extensive report to the local medical coroner, as no certificate of natural death can be written. The coroner inspects the body, informs the local prosecutor, and hands over the physician's report. The prosecutor checks the facts of the case against the law and jurisprudence, then writes an opinion about the main issues, with advice for the chief prosecutor. He then reports the case to the national prosecutors, who meet regularly. It is this group that decides on the basis of the facts, the advice, and their combined view whether to prosecute or not. The final decision is made by the Secretary of Justice. In the last cases, the process extended over a period of approximately 5 months.

The 15 pages of the protocol, version 29/9/2004, reflect the intentions for transparency and accountability in each step of the procedure, noting all the details of the process, and taking into account the responsibility of all the participants, including the child's parents and their views.

For some people this protocol is a sure sign of a steeper slide down the slippery slope of active euthanasia in the Netherlands; for others it is a brave effort to deal responsibly with the realities of medicine and the law that fall outside the usual medical and legal categories.

The third important recent development in Dutch bioethics is the publication in December 2004 of a report with the long title "Searching for Norms for Physician Intervention When Help Is Requested to End Life in Case of Emotional Suffering." The report is produced by a Commission of the RDMA, chaired by Prof. J.H. Dijkhuis, a psychologist, in the wake of the "Brongersma Case," concerning the active termination of life of an 86-year-old man by his physician in 1998.

Some details of the case are necessary to understand the deliberations of the Commission, the report's conclusions, and the broader issues in the Dutch societal debate. For years, Brongersma, an elderly, single man, had wrestled with a number of common predicaments of the elderly, social, existential, and physical. For him life was meaningless. Over a long period of time, he asked his family physician, Sutorius, to help him die. After going through the procedure of securing second opinions from a colleague family physician and a psychiatrist, who both concurred but on different grounds, he terminated his patient's life and reported it to the authorities.

In successive court procedures in a lower court, a higher court, and the Dutch Supreme Court, the legal question centered on two issues: the presence 
of a medical disease falling within the "medical domain," as it was called, and the presence of a situation of "force majeure," a situation of emergency, in Dutch a noodtoestand. In this circumstance the physician is faced with a dilemma in which he feels he really has no other choice but to respond to the duty to alleviate suffering versus the duty to protect life.

The Supreme Court clearly ruled for limiting justifiable physician involvement in voluntary active euthanasia or assisted suicide to those cases where there is the existence of a disease that causes unbearable suffering. The court did not recognize the legitimacy of ending life in cases of loss of physical function in old age and existential feelings of the lack of meaning in life. Doubt remained in these latter cases about whether the suffering could be verified medically even though it was experienced as unbearable.

The Court's opinion was received with ambivalence, both inside and outside the medical profession. ${ }^{4}$ The argument of the medical domain was viewed as inconsistent on two grounds. First, the medical domain usually is not conceived as a fixed entity, but shaped by time and culture. Second, also inconsistent was the stipulation that although existential anguish can be a reality of life addressed by physicians, at the same time, according to the Court's decision, they are not permitted "to form a judgment concerning whether the qualities of that suffering are unbearable, hopeless or incurable."

The assignment of the RDMA's Dijkhuis Commission was to answer the following questions:

1. Are there inherent limits to the present manner of legitimizing life-ending interventions by a physician? If so, what are these limits? What does that imply for the justification of the interventions of physicians in those cases where the patients' request for help to end life is based primarily in their loss of the will to live due to loss of companionship, physical disabilities, and generally reduced overall function.

2. Is there, in the light of this analysis, reason for either adaptation or extension of the presently accepted norms and rules concerning help to end life after a request? If so, how and in what direction?

The answers of the report reflect both the ambivalence toward the Brongersma case and the lack of professional consensus in medicine. It appears, based on the information of invitational conferences with various groups of physicians, that the number of requests in these cases, existential suffering without an incurable medical disease, is very low. Physicians tend to be hesitant in recognizing issues of existential suffering as falling within the domains of legitimate termination of life, and, if there are cases, they are usually considered "borderline cases." There appears to be a lack of consistent appreciation and assessment of that particular type of suffering.

Four options are described in the report's conclusion:

- the choice for a strict limitation to the medical professional domain

- an extended, but not limitless professional domain

- a domain that is shared by different professional caretakers

- the choice for assisted suicide outside of the medical profession.

The commission's advice to the RDMA is a choice for the second option with the following arguments: 
1. Unbearable and hopeless suffering is not confined to people with a classifiable somatic or psychic disorder.

2. The present legal demarcation does not solve the practical problems and is a denial of the complexity (of the assessment) of suffering.

3. A certain weight must be given to the different ways in which physicians see their role and tasks in these issues.

4. In the future it is to be expected that there will be an increase rather than a decrease of this type of request.

The Commission ends its report with a plea for loosening the strict limits of the Hoge Raad, based on the reality that physicians and others are involved in caring for people with existential suffering, even though the instruments for assessing this condition are undeveloped and not based on consensus. Yet the Commission pleads also for a certain limited space for developments to integrate "suffering of life" in the present procedures. That is possible within the confinements of the present law. The law stipulates that physicians need to assess unbearable and hopeless suffering, but does not prescribe how this assessment should take place.

The Commission's recommendations to the RDMA are in line with these suggestions:

1. to promote continued debate on the legitimate limits of the physicians' role in requests to end life

2. to develop procedural guidelines to deal with borderline cases within the present legal context

3. to work with other caretakers and their organizations to develop needed expertise for these cases, including options for support and consultation

4. to recognize the diversity of opinions and responses among physicians in dealing with requests to assist in ending life in cases of this kind

5. to participate actively in the social debate about the options for assisted suicide and the clarification of the role of physicians' participation

6. to be advised on a yearly basis by a permanent commission in this area and establish policy on the basis of their recommendations.

\section{Conclusion}

Heinrich Heine once said that he would go to the Netherlands when the world comes to an end, because everything in this country happens 50 years later. We have come a long way from Heine's assessment of the Dutch. Certainly much is going on in the Low Countries, but it is debatable whether the direction is forward or backward.

In the healthcare system, developments seem to be shifting away from traditional welfare systems based on social cohesion, taking a distanced approach from solidarity as a guiding social principle, and embracing competition and "the marketplace." In the area of end-of-life care, the Dutch seem to continue their particular brand of dealing with the issue that all persons are mortal and that individuals should have the option to give form and substance to the ending of their life. 


\section{Notes}

1. Dubbink W. Assisting the invisible hand: Contested Relations between Market, State and Civil Society. Dordrecht: Kluwer Academic Publishers; 2003.

2. Sauer PJJ, Chambers TL, Crawley FP, Gill D, Kurtz R, de Lourdes Levy M et al. Ethical dilemmas in neonatology: Recommendations of the Ethics Working Group of the CESP. European Journal of Paediactrics 2001;160:364-8.

3. Verhagen E, Sauer PJJ. The Groningen Protocol-Euthanasia in severely ill newborns. New England Journal of Medicine 2005;352(10):959-62.

4. See Schalken TM. Commentary Hoge Raad Case AE8771, case number 00797/02, The Netherlands versus Sutorius. Ned. Tschr. Gezondheidsrecht 2003;3:237-9. 